\title{
The Permostridulidae fam. n. (Panorthoptera), a new enigmatic insect family from the Upper Permian of France
}

\author{
OLIVIER BÉTHOUX ${ }^{1,2}$, ANDré NEL ${ }^{1}$, JEAN LAPEYRIE $^{3}$ and GEORgES GAND ${ }^{4}$ \\ ${ }^{1}$ Laboratoire d'Entomologie and UMR CNRS 8569, Muséum National d'Histoire Naturelle, 45 rue Buffon, F-75005 Paris, France; \\ e-mail: anel@mnhn.fr \\ ${ }^{2}$ UMR Botanique et Bioinformatique de l'Architecture des Plantes, CIRAD - CNRS, TA40/PS2, 2196 Bd. de La Lironde, F-34398 \\ Montpellier France; e-mail: bethoux@cirad.fr \\ ${ }^{3}$ Corniche de Fontbonne, F-34700 Lodève, France; e-mail: jlapeyri@club-internet.fr \\ ${ }^{4}$ Centre des Sciences de la Terre, UMR 5561 CNRS, Université de Bourgogne, 6 Boulevard Gabriel, F-21000 Dijon, France; \\ e-mails: umr5561@satie.u-bourgogne.fr or georges.gand@wanadoo.fr
}

Key words. Insecta, Neoptera, Panorthoptera, Permostridulidae fam. n., Permostridulus brongniarti gen. n. \& sp. n., Upper Permian, France, stridulatory apparatus.

\begin{abstract}
The unusual wing characters of the Permian insect Permostridulus brongniarti gen. n., sp. n. justifies the creation of a new family, the Permostridulidae fam. n., within the Panorthoptera. Phylogenetic relationships with the extinct order Caloneurodea, related to the Orthoptera (crickets, grasshoppers), are assumed. This assumption suggests an occurrence of the Permostridulidae at least since the Upper Carboniferous. The most prominent feature of the wing venation is a stridulatory apparatus, nonhomologous with those previously known in "panorthopterid" lineages. This is the oldest recorded sound-producing device of an animal.
\end{abstract}

\section{INTRODUCTION}

Despite the recent recognition of the new insect order Mantophasmatodea Klass et al., 2002, the phylogeny of the "Polyneoptera" is still partly unresolved; even its monophyly is uncertain (Wheeler et al., 2001a, b). Despite their antiquity and their biodiversity peak during the Permian (Labandeira \& Sepkoski, 1993; Jarzembowski \& Ross, 1996) the Palaeozoic "polyneopterous" insects are rarely considered in phylogenetic analyses. Nevertheless, the usefulness of inclusion of fossil taxa in phylogenies is widely admitted (Smith, 1994).

Within the Polyneoptera, the Panorthoptera Crampton, 1928 (sensu Béthoux \& Nel, 2002) are a well-defined clade, including Orthoptera and closely related Palaeozoic and Triassic clades of ordinal rank (Titanoptera, Caloneurodea) (Béthoux \& Nel, 2002). Nevertheless, the relationships among these orders are still unknown.

Here we report the discovery of three Upper Permian fossil wings belonging to a new species, Permostridulus brongniarti gen. n., sp. n. This species can be assigned to the Panorthoptera but, because of its unusual combination of traits, the new species cannot be attributed to any of the known orders with confidence. We provisionally propose to include it in a new family of uncertain ordinal relationships.

\section{MATERIAL AND METHODS}

The venation patterns and vein widths were drawn with a stereomicroscope and camera lucida direct from the fossil surface, dry and under alcohol. Both imprints and counter-imprints were used when available. As far as possible (depending on the relief of the rock containing the fossils), the relief of the wing veins is restored as viewed dorsally, using light-mirroring technique, illuminating the fossils from the lower right.

We follow the nomenclature of insect wing venation elaborated for the Panorthoptera ( $\mathrm{R}$ - Radius; RA - anterior Radius; $\mathrm{RP}$ - posterior Radius; $\mathrm{M}$ - Media; CuA - anterior Cubitus; CuP - posterior Cubitus; $\mathrm{CuPa}$ - anterior branch of $\mathrm{CuP}$; $\mathrm{CuPa} \alpha$ anterior branch of $\mathrm{CuPa}$; $\mathrm{CuPa} \beta$ - posterior branch of $\mathrm{CuPa}$; $\mathrm{CuPb}$ - posterior branch of CuP; AA1 - first anterior Anal; AA2: second anterior Anal) (see Béthoux \& Nel, 2002).

\section{TAXONOMIC PART}

Panorthoptera Crampton, 1928, (sensu Béthoux \& Nel, 2002)

Order incertae sedis [possibly Caloneurodea]

Family Permostridulidae, fam. $\mathbf{n}$.

Type genus Permostridulus gen. n. (the only genus included)

Diagnosis. Forewing: $\mathrm{ScP}$ basally close to $\mathrm{R}$, diverging towards anterior wing margin just distal of origin of RP; MA with two long simple branches, MP with 4-5 branches; $\mathrm{CuA}+\mathrm{CuPa} \alpha$ and $\mathrm{CuPa} \beta$ simple and straight; area between $\mathrm{CuA}+\mathrm{CuPa} \alpha$ and $\mathrm{CuPa} \beta$ very narrow; stridulatory apparatus composed of a bow of strengthened and fused cross-veins in area between $\mathrm{CuPa}$ and $\mathrm{CuPb}$ (at least in some specimens); AAl basally arched.

\section{Genus Permostridulus gen. $n$.}

Type species. Permostridulus brongniarti $\mathrm{sp} . \mathrm{n}$.

Etymology. "Permo" after the Permian age of the type deposits and "stridulus" after the presence of a stridulatory apparatus in the cubital area.

Diagnosis. That of the family (see above). 
Permostridulus brongniarti sp. $\mathbf{n}$.

(Fig. 1)

Diagnosis. That of the family.

\section{Description.}

Holotype specimen Ld LAP 499ab (Fig. 1A, B). Part and counterpart of an incomplete left forewing with part of anterior wing margin, distal ends of some veins, posterior wing margin and apex missing, distally disrupted with parts preserved in different rock planes; preserved part about $33.1 \mathrm{~mm}$ long and about $11.8 \mathrm{~mm}$ wide; anterior wing margin posteriorly bowed; cross-veins between anterior wing margin and $\mathrm{ScP}$ straight and parallel; basal parts of ScP and R closely parallel; ScP reaching anterior wing margin just distal of basal branch of RA; RA anteriorly pectinate with four simple sigmoidal branches; RA branched $8.0 \mathrm{~mm}$ distal of its origin; first branch of RP $6.9 \mathrm{~mm}$ distal of its origin; RP with at least five branches but without clear organization, i.e., neither pectinate nor dichotomous; origin of MA just basal of that of RP; MA slightly sigmoidal basal of its unique fork $(9.2 \mathrm{~mm}$ distal of its origin); branches of MA simple in preserved part; MP forked about $3.4 \mathrm{~mm}$ distal of its origin, with at least five branches but without clear organization; $\mathrm{CuPa}$ fused with $\mathrm{CuA}$, thus no free $\mathrm{CuPa} \alpha$; strongly convex $\mathrm{CuA}+$ $\mathrm{CuPa} \alpha$ and strongly concave $\mathrm{CuPa} \beta$ both straight and simple; $\mathrm{CuPb}$ posteriorly bowed in its basal part, distally straight and simple; area between $\mathrm{CuPa}$ and $\mathrm{CuPb}$ with a strengthened bow of fused cross-veins; AAl anteriorly bowed in its basal part (opposite posterior bow of $\mathrm{CuPb}$ ), distally parallel to $\mathrm{CuPb}$, simple and straight; two long and curved cross-veins in area between R and M/ MA; cross-veins reticulated in basal part of areas between $\mathrm{CuPa}$ and $\mathrm{CuPb}$ and between $\mathrm{CuPb}$ and $\mathrm{AA} 1$; cross-veins strengthened and strongly approximate in basal parts of areas between $\mathrm{CuPb}, \mathrm{AAl}$, and most posterior vein (posterior wing margin or AA2?), but spaced out distal parts of these areas; cross-veins straight, rarely reticulated, and regularly spaced in distal part of wing.

Specimen Ld LAP 527ab (Fig. 1C). Part and counterpart of an incomplete right wing with distal part and posterior wing margin missing, exact width unknown; preserved length $17.0 \mathrm{~mm}$; $\mathrm{ScP}$ close to $\mathrm{R}$ basally but diverging abruptly towards anterior wing margin distal of origin of RP; RA with two simple anterior branches in preserved part; RA branched $6.1 \mathrm{~mm}$ distal of its origin; $\mathrm{RP}$ branched $4.3 \mathrm{~mm}$ distal of its origin; RP with four branches in preserved part; both MA and MP at least with one fork preserved; $\mathrm{CuPa} \alpha$ very short basal of its fusion with $\mathrm{CuA} ; \mathrm{CuA}+\mathrm{CuPa} \alpha$ and $\mathrm{CuPa} \beta$ simple, straight, slightly bowed towards apex in distal part; area between $\mathrm{CuPa} \beta$ and $\mathrm{CuPb}$ broad in preserved part; two long, oblique and sigmoidal cross-veins between R and MA; cross-veins in basal part of area between $\mathrm{CuPa}$ and $\mathrm{CuPb}$ reticulated; in others areas, cross-veins not reticulated, straight and regularly spaced out.

Specimen Ld LAP 526ab (Fig. 1D). Part and counterpart of an incomplete right wing, with wing base and basal posterior part missing; preserved length $31.1 \mathrm{~mm}$, estimated length about $33.5 \mathrm{~mm}$; estimated width 10.0 $\mathrm{mm}$ (opposite end of $\mathrm{CuPb}$ ); $\mathrm{ScP}$ very close to $\mathrm{R}$ basally but diverging towards anterior wing margin opposite basal third of wing; ScP reaching anterior wing margin opposite end of $\mathrm{CuPab}$ on posterior wing margin, about midway along wing; anterior branches of RA not well defined, replaced by a reticulated net of cross-veins in area between RA and anterior wing margin; RP branched $6.7 \mathrm{~mm}$ distal of its base; branches of RP organized into simple anterior branches and forked posterior branches; base of MA basal of that of RP; MA slightly sigmoidal at its base, forked $3.3 \mathrm{~mm}$ distally; anterior branch of MA with a very distal short fork; MP dichotomously branched, with at least four branches reaching posterior wing margin; $\mathrm{CuA}+\mathrm{CuPa} \alpha, \mathrm{CuPa} \beta, \mathrm{CuPb}$, and $\mathrm{AA} 1$ simple and straight in their preserved parts; $\mathrm{CuA}+\mathrm{CuPa} \alpha$ and $\mathrm{CuPa} \beta$ parallel; $\mathrm{CuPb}$ and $\mathrm{AA} 1$ parallel; both sets of parallel veins converging near posterior wing margin; no strengthened bow of fused cross-veins in area between $\mathrm{CuPa}$ and $\mathrm{CuPb}$ but a net of reticulated cross-veins; crossveins in distal part of wing regularly spaced out, not or rarely reticulated.

Material. Holotype specimen Ld LAP 499ab, paratypes specimens Ld LAP 526ab, Ld LAP 527ab, allin Collection Lapeyrie, Musée Fleury, Lodève, France.

Geological settings. Upper Permian, Kungurian / Kazanian (Béthoux et al., 2002); France, Lodève basin, Salagou Formation; holotype specimen Ld LAP 499ab: Dio "F20" site; paratype specimen Ld LAP 526ab: Le Devès "F40" site; paratype specimen Ld LAP 527ab: Le Mourrel "F41" site (for localization see Garric, 2000).

Etymology. In honour of Prof. C. Brongniart (1859-1899), who provided valuable works on Carboniferous insects.

\section{PHYLOGENETIC RELATIONSHIPS}

Permostridulidae fam. n. are assigned to the supraordinal clade Panorthoptera Crampton, 1928 sensu Béthoux \& Nel, 2002, because of the synapomorphic branching of $\mathrm{CuPa}$ into $\mathrm{CuPa} \alpha$ and $\mathrm{CuPa} \beta$. The Permostridulidae can be excluded from all the "panorthopterid" orders (Orthoptera, Titanoptera, Caloneurodea) because of the following forewing characters: (1) MP with numerous branches; and (2) presence of a stridulatory apparatus in cubital area (see below). It can be excluded from Orthoptera owing to these characters: (3) presence of narrow area between anterior wing margin and $\mathrm{ScP}$; (4) $\mathrm{CuA}+\mathrm{CuPa} \alpha$ simple; and (5) $\mathrm{CuA}+\mathrm{CuPa} \alpha$ and $\mathrm{CuPa} \beta$ close together and parallel-sided for a considerable distance. The Permostridulidae can be excluded from the Titanoptera on the basis of characters (4) and (5), plus character (6) absence of alternation of convex and concave cross-veins in areas of middle part of wing. It can be excluded from the Caloneurodea by characters (7) RA with numerous branches and (8) MA with one fork at least. This very unusual combination of characters and the occurrence of an autapomorphic stridulatory apparatus could support the creation of a new order, but additional information concerning the hindwing and body structures is required. 

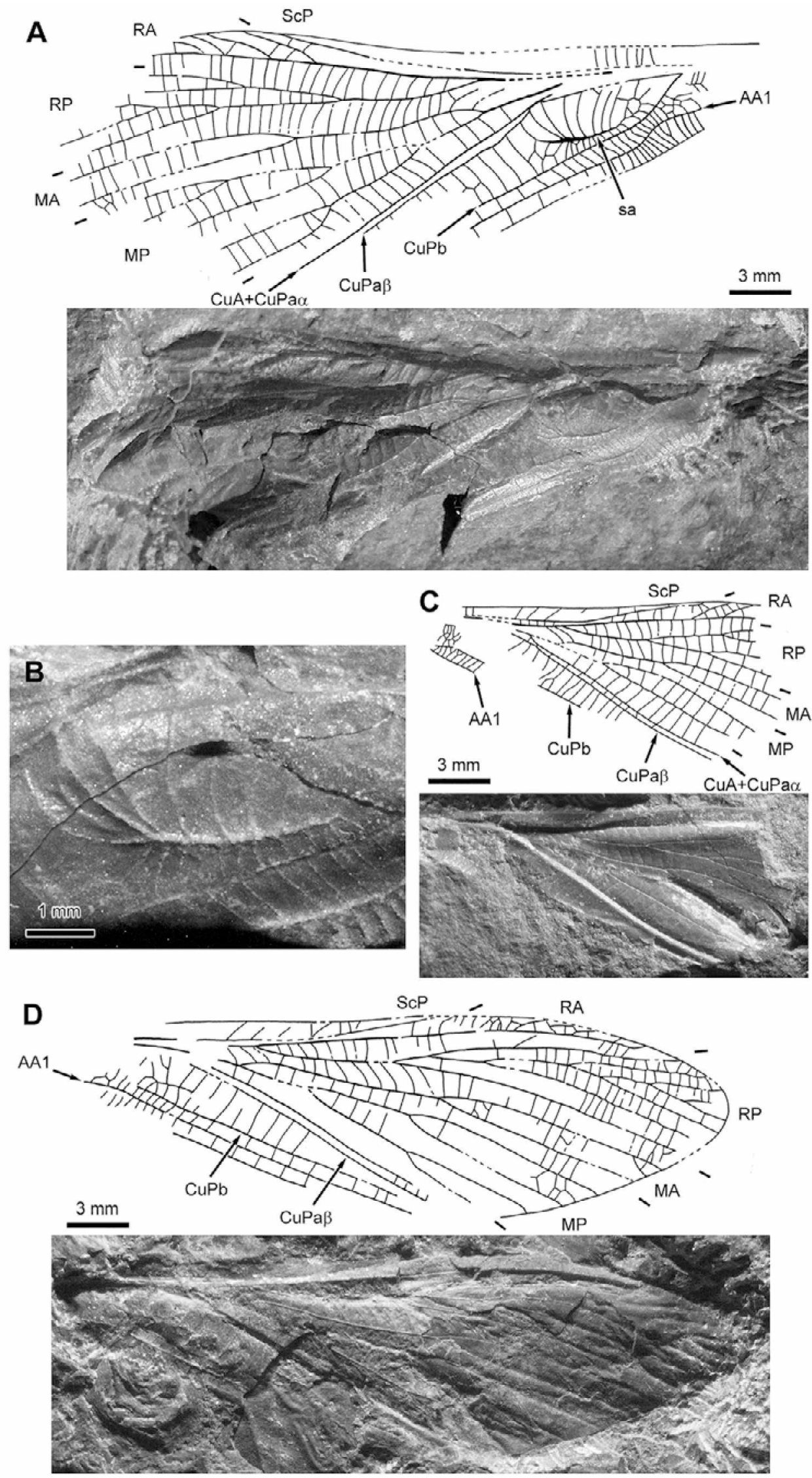

Fig 1. Permostridulus brongniarti gen. n., sp. n. A - holotype specimen Ld LAP 499: reconstruction and photograph (part, lightmirrored); sa - stridulatory apparatus; B - holotype specimen Ld LAP 499: detail of the stridulatory apparatus (counterpart, lightmirrored, reversed); C - specimen Ld LAP 527: reconstruction and photograph (part, reversed); D - specimen Ld LAP 526: reconstruction and photograph (part). 
The Permostridulidae share with the Caloneurodea characters (3), (4), and (5). These apomorphic characters (for Panorthoptera) support close (possibly sister group) phylogenetic relationships between the Permostridulidae and the Caloneurodea. Because the Caloneurodea are recorded in the Upper Carboniferous (Carpenter, 1992), the Permostridulidae could also have been present during this period.

\section{STRIDULATORY APPARATUS}

The bow of fused cross-veins in the basal part of the wing (specimen LAP 499ab; Fig. 1B) is interpreted as a stridulatory apparatus because it is similar to, although nonhomologous with the stridulatory structures present in several Orthoptera, i.e. the extant and fossil Ensifera (crickets) and the fossil family Mesoedischiidae Sharov, 1971 (Béthoux \& Nel, 2002). These structures are located in the posterobasal part of the forewing in all these taxa. In the Orthoptera, the stridulatory apparatus involves either the anal area (in Tettigoniidae and Mesoedischiidae) or the area between $\mathrm{CuA}$ and the branches of $\mathrm{CuP}$ and modifies the course of the branch $\mathrm{CuPa} \beta$, unlike in Permostridulus. The assumption that this structure is stridulatory is also supported by the occurrence of an arched AA1 and of the strengthening of the nearest cross-veins, all features present in the wings of stridulating Orthoptera.

Because all the "wing-based" sound producing apparatuses of the "Polyneoptera" are located in forewings, it is assumed that the specimen LAP 499ab is a forewing. Moreover, hindwings of most "Polyneoptera" are more or less dedicated to lift production during flight, correlated with a high deformability (Herbert et al., 2000), incompatible with the strengthened structures observed in specimen LAP 499ab. The absence of a developed stridulatory apparatus in specimen Ld LAP $526 \mathrm{ab}$ suggests that this device was present only in forewings, in only one of the forewings, or only in one of the sexes (probably the males).

If one accepts these assumptions, this is the oldest record of a sound-producing animal device. Moreover, it is not homologous with previously known "panorthopterid" insect apparatuses, and thus provides additional support for the opinion that stridulatory behaviour appeared convergently in diverse "panorthopterid" lineages (Gwynne, 1995). This discovery suggests that our knowledge of insect morphological disparity during the Permian has to be refined.

\section{CONCLUSION}

The Permian is a unique period of ordinal extinction but also of high ordinal diversity in insects (Carpenter, 1992; Labendeira \& Sepkoski, 1993; Jarzembowski \& Ross, 1996; Belayeva et al., 2002). The discovery of Permostridulidae fam. n. strongly supports the hypothesis that the Panorthoptera reached a peak of taxonomic diversity during the end of the Palaeozoic: the two extinct orders, Caloneurodea and Titanoptera, plus the Orthop- tera, are known or their occurrence is inferred for the Permian owing to their phylogenetic relationships (Gorokhov, 2001). The resolution of ordinal relationships within the "super-order" Panorthoptera may help to resolve the phylogeny of its extant representatives (Orthoptera) and of other extant "polyneopterous" orders. Because of their unusual morphology, the Permostridulidae may have an important role in solving this problem.

ACKNOWLEDGEMENTS. We thank Prof. Dr. M. Engel (University of Kansas) and an anonymous referee for their constructive comments on the manuscript. This work was supported by a grant "Germaine Cousin" from the "Société Entomologique de France" (year 2001) and by the UMR 8569 and UMR 5120 of French CNRS.

\section{REFERENCES}

Belayeva N.V., Blagoderov V.A., Dmitriev V.Y., Eskov K.Y., Gorokhov A.V., Ivanov V.D., Kluge N.Y., Kozlov M.V., Lukashevich E.D., Mostovski M.B., Novokshonov V.G., Ponomarenko A.G., Popov Y.A., Pritykina L.N., Rasnitsyn A.P., Shcherbakov D.E., Sinitshenkova N.D., Storozhenko S.Y., SuKatsheva I.D., Vishniakova V.N., VRSansky P. \& ZHERIKHIN V.V. 2002: History of Insects. Kluwer Academic Publishers, Dordrecht, $517 \mathrm{pp}$.

BÉTHoux O. \& NeL A. 2002: Venational pattern and revision of Orthoptera sensu nov. and sister groups. Phylogeny of Palaeozoic and Mesozoic Orthoptera sensu nov. Zootaxa 96: 1-88.

Béthoux O., Nel A., Lapeyrie J., Gand G. \& Galtier J. 2002 : Discovery of the genus Iasvia Zalessky, 1934 in the Upper Permian of France (Orthoptera: Ensifera: Oedischiidae). Geobios 35: 293-302.

Carpenter F.M. 1992: Superclass Hexapoda. In: Moore R.C. \& Kaesler R.L. (eds): Treatise on Invertebrate Paleontology. The Geological Society of America. and University of Kansas, Boulder, Colorado, (R), Arthropoda 4, 3/4: xxii +655 pp.

CRAMPTON G.C. 1928: The grouping of the insect orders and their lines of descent. The Entomologist 61: 82-85.

GARRIC J. 2000: Les rigoles fossilifères du Saxonien du bassin permien de Lodève (Languedoc, France) [Saxonian fossiliferous rills from the permian Lodève basin (Languedoc, France)]. Bull. Soc. Hist. Nat. Autun 174: 7-48.

Gorokhov A.V. 2001: On the higher classification of the Polyneoptera. Acta Geol. Leopold. 24: 11-56

Gwrnne D.T. 1995: Phylogeny of the Ensifera (Orthoptera): A hypothesis supporting multiple origins of acoustical signalling, complex spermatophores and maternal care in crickets, katydids and weta. J. Orthoptera Res. 4: 203-218.

Herbert R.C., Young P.G., Smith C.W., Wootton R.J. \& Evans K.E. 2000: The hind wing of the desert locust (Schistocerca gregaria Forskal). III. A finite element analysis of a deployable structure. J. Exp. Biol. 203: 2945-2955.

JARZEMBOWSKI E.A. \& Ross A.J. 1996: Insect origination and extinction in the Phanerozoic. In: Hart M.B. (ed.): Biotic from Extinction Events. Geological Society Special Publication No. 102, pp. 65-78.

Klass K.-D., Zompro O., Kristensen N.P. \& Adis J. 2002: Mantophasmatodea: a new insect order with extant members in the Afrotropics. Science 296: 1456-1459.

Labendeira C.C. \& SePKoski J.J. 1993: Insect diversity in the fossil record. Science 261: 310-315.

Sharov A.G. 1971: Phylogeny of the Orthopteroidea. Israel Program for Scientific Translations, Jerusalem, vi $+223 \mathrm{pp}$. 
Sмiтh A.B. 1994: Systematics and the Fossil Record: Documenting Evolutionary Patterns. Blackwell, London, i-vii + 223 pp.

Wheeler W.C., Whiting M., Wheeler Q.D. \& CarPenter J.M. 2001a: The phylogeny of the extant hexapod orders. Cladistic 17: $113-169$.
Wheeler W.C., Whiting M., Wheeler Q.D. \& Carpenter J.M. 2001b: Erratum. Cladistics 17: 403-404.

Received February 24, 2003; revised July 1, 2003; accepted August 28, 2003 